\title{
DIGITAL PULSE GENERATOR FOR MULTIPHASE BOST CONVERTER
}

\author{
Matej BEREŠ, Dobroslav KOVÁČ \\ Department of Theoretical and Industrial Electrical Engineering, Faculty of Electrical Engineering and Informatics, \\ Technical University of Košice, Letná 9, 04200 Košice, Slovak Republic, \\ tel. +421 55602 2516, +421 55602 2801, e-mail: matej.beres@tuke.sk, dobroslav.kovac@tuke.sk
}

\begin{abstract}
The paper deals with a new method of design of digital pulse generator, which is specially designed for multiphase converters. The advantage of this control method lies in its applicability to the microcontrollers. The generator is capable of generating the PWM pulses for a variable number of legs in the range of 1-10. In the article, the results from 6 legs connection are presented. By the utilization of the several legs, the generator can generate pulses with phase shift and frequency of $50 \mathrm{kHz}$. The size of the phase shift depends on the number of legs. The paper describes the functions of the individual parts of the generator, which are shown schematically. The simulations and experimental models were built and measured to verify the theoretical assumptions. The paper contains also the PCB design and practical construction notes.
\end{abstract}

Keywords: digital pulse generator, multiphase converters, $P$ WM pulses

\section{INTRODUCTION}

In present times, the electricity production by solar panels utilization is a very actual and discussed problem. There is a significant endeavor to improve the efficiency of energy conversion. In order to succeed, it is imperative to use a converter, which would be able to obtain the maximum energy from the solar panel. Such type of a converter is represented by the connection of multiphase converter, described in [1], [2]. For its control, a pulse generator, that generates pulses with individual phase shift for each leg is needed.

This paper presents a new type of digital multiphase pulse generator $(D M P G)$. The advantage of the proposed generator lies in its relatively simple design, high precision, low cost, wide variety of signal generation and control simplicity itself. The generator is able to generate $P W M$ (Pulse Width Modulation) signal with the desired frequency. In this case, it has frequency of $50 \mathrm{kHz}$. For the purpose of main DMPG properties description, the paper is divided into several chapters.

\section{GENERATOR'S OPERATION PRINCIPLE}

The DMPG consists of two basic parts. The first part is created from adjustable pulse generator and the pulse divider. The second part is constructed by the legs themselves. This part of the generator is creating the $P W M$ signals.

\section{A Pulse generator and divider}

The main task of this part is to generate phase shifted signals for the proposed legs. Thus, the size of the pulse phase shift depends on the number of legs. It is important to note, that the frequency remains unchanged. The pulse generator and divider consist in total from 4-bit $B C D$ (Binary Coded Decimal) counter, 10-bit decoder, adjustable pulse generator and logic gates (see Fig. 1).

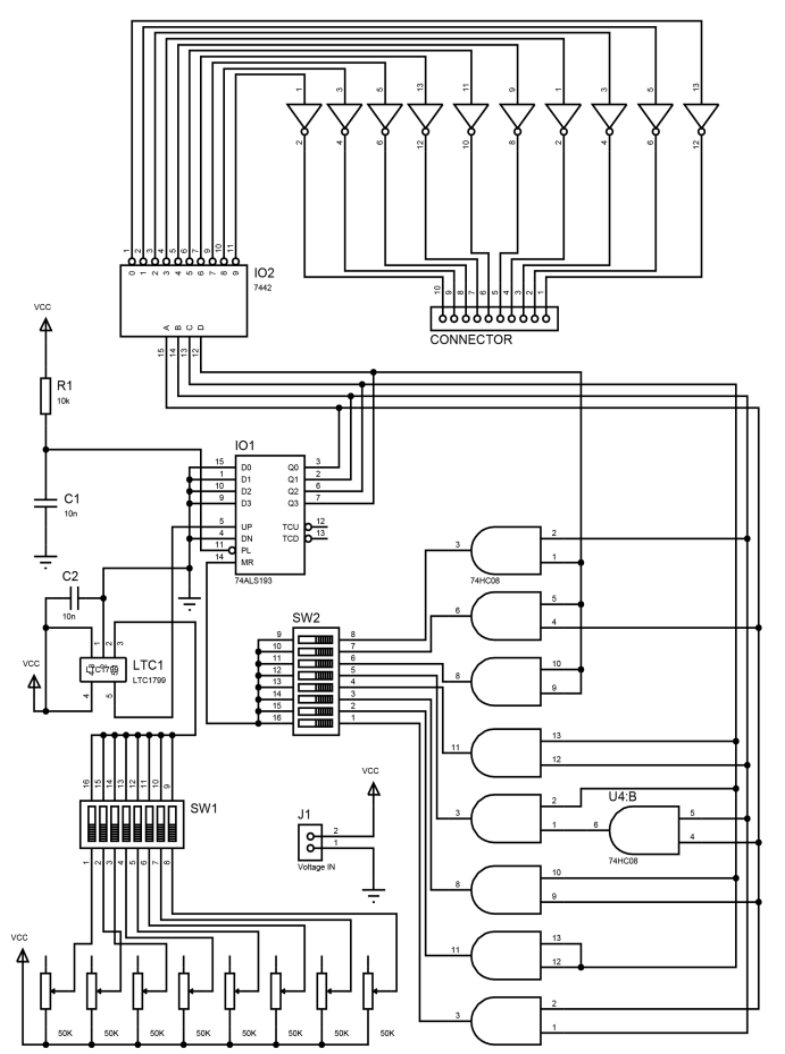

Fig. 1 Pulse generator and divider schematics

Phase shifted pulses generation is provided by two integrated circuits: 4-bit $B C D$ counters IC (integrated circuit) 74193 and 10-bit decoder IC 7442. The counter is able to count from 0 to 15 in binary form. For 6 legs converter, the range of the used counter must be reduced. For the counting reduction, the logical gates of AND type with two inputs (IC 7408) are used. Into its first input, the output of the second bit of counter is connected. Into its second input, the output of the third bit of counter is connected. Thus, the counter is cleared at the moment, when combination 0110 occurs on its output bits. With such 
connection, the counting range can be reduced, in dependence on the number of legs. Each change of the number of legs requires also the change of the input frequency. This requirement is fulfilled by the usage of the pulse generator based on IC type LTC1799. The frequency change in this case is reached by the change of resistor $\mathrm{R}$ value (see Fig.2) [3]. It is secured by the 8-bit switches array SW1 (see Fig. 1), but the important note is, that only the one switch can be in switch-on position. The rest could be only in switch-off position. This array is interconnected with the scale of potentiometers, which have set the different individual values. It is possible to calculate their rate by the following equation:

$$
f_{\text {osc }}=10 \cdot 10^{6} \cdot\left(\frac{10.10^{3}}{N \cdot R}\right)[\mathrm{Hz}]
$$

For 6 legs converter and required frequency $50 \mathrm{kHz}$ per one leg (300 kHz total frequency of the pulse generator), we can choose:

$R=10.10^{6}\left(\frac{10.10^{3}}{N \cdot 300.10^{3}}\right)$

where " $f_{\text {osc }}$ " is a frequency of the pulse generator. " $R$ " is the calculated resistor value for the desired frequency. The parameter " $N$ " is a pulse generator constant. This constant may have values $1,10,100$. This value depends on the connection of pulse generator DIV (DIVider) pin, (see Fig. 2 ). In described case, the value of $N$ is set to 100 . According the equation (1), the resistance for the remaining legs is calculated, too.

$R=3.33 k \Omega$

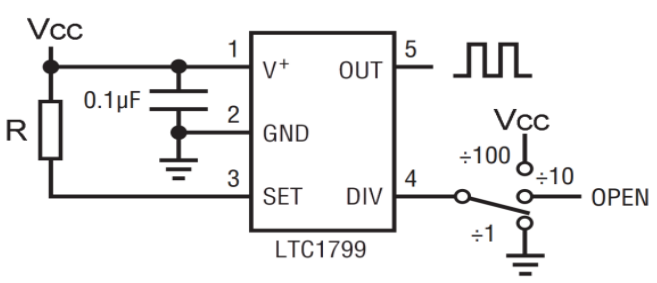

Fig. 2 Basic connection of LTC1799 pulse generator

For the different number of legs, the different clock frequency is needed, as well as different value of resistances (see Table 1).

Table 1 Frequencies and resistances for the selected number of legs

\begin{tabular}{|c|c|c|}
\hline Legs num. & Frequency $[\mathrm{kHz}]$ & Resistance $R[\mathrm{k} \Omega]$ \\
\hline 1 & 50 & 20 \\
\hline 2 & 100 & 10 \\
\hline 3 & 150 & 6.667 \\
\hline 4 & 200 & 5 \\
\hline 5 & 250 & 4 \\
\hline 6 & 300 & 3.33 \\
\hline 7 & 350 & 2.86 \\
\hline 8 & 400 & 2.5 \\
\hline 9 & 450 & 2.22 \\
\hline 10 & 500 & 2 \\
\hline
\end{tabular}

The basic frequency for one leg converter can be chosen arbitrarily, but the multi-legs connections would respect the multiply effect of basic frequency given by Table 1 .

If the number of legs is changed, the counting range of IC 74193 counter has to be changed, too. This change is provide by array of switches SW2 (see Fig. 1), with the same condition as in the case of SW1, which means that only one switch can be in switch-on position and the rest have to be in switch-off position.

Finally, the output values of the decoder are inverted by logic gates (see Fig. 3).

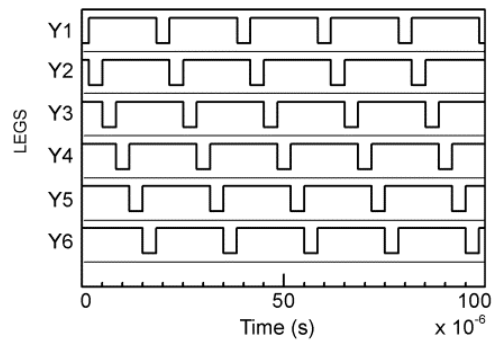

a)

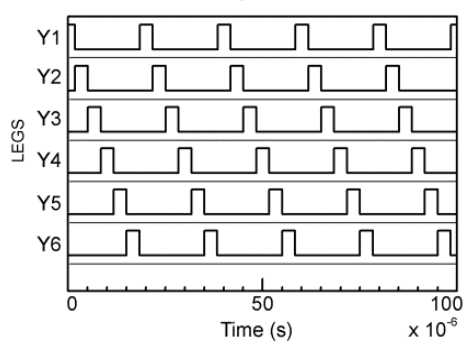

b)

Fig. 3 a) Non inverted output from decoder, b) inverted output from decoder

\section{$B$ Legs of the PWM generator}

The legs are designed in a way to be able to change their number and each leg of generator has to be identical to other one. Due to this fact, the following description will be done for only one leg.

Each leg of the generator is able to generate a PWM signal with a resolution of 400 discrete positions. Thus, the generator counter is counting to 400 every $20 \mu$ s (see Fig. 4).

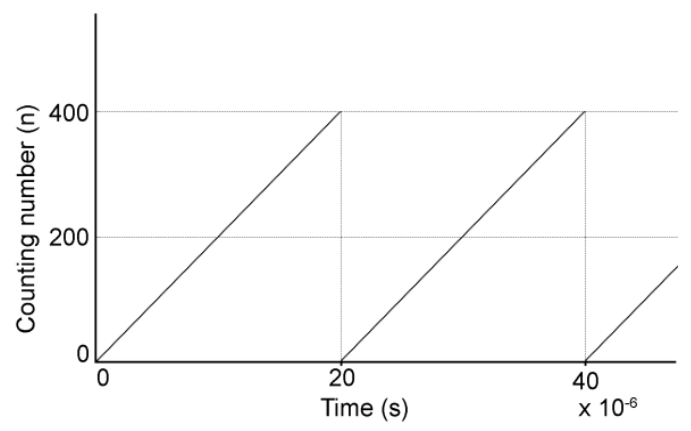

Fig. 4 Resolution of PWM

In order to achieve such resolution for output signal with $50 \mathrm{kHz}$ frequency, it is necessary to connect the pulse signal with frequency of $20 \mathrm{MHz}$ to the input of the counter. Three 4-bit counters are connected in series, because one 4- 
bit counter cannot count to 400 (see Fig. 5). Therefore, the maximum counting value can be settled as 4095 and for counting to 400 , it is sufficient to use only the first output bit from the third counter. The reset of all counters is realized by the synchronization pulse with frequency 50 $\mathrm{kHz}$, which is generated by the divider. In this way, the counter resets and starts from the 0 after each sync pulse.

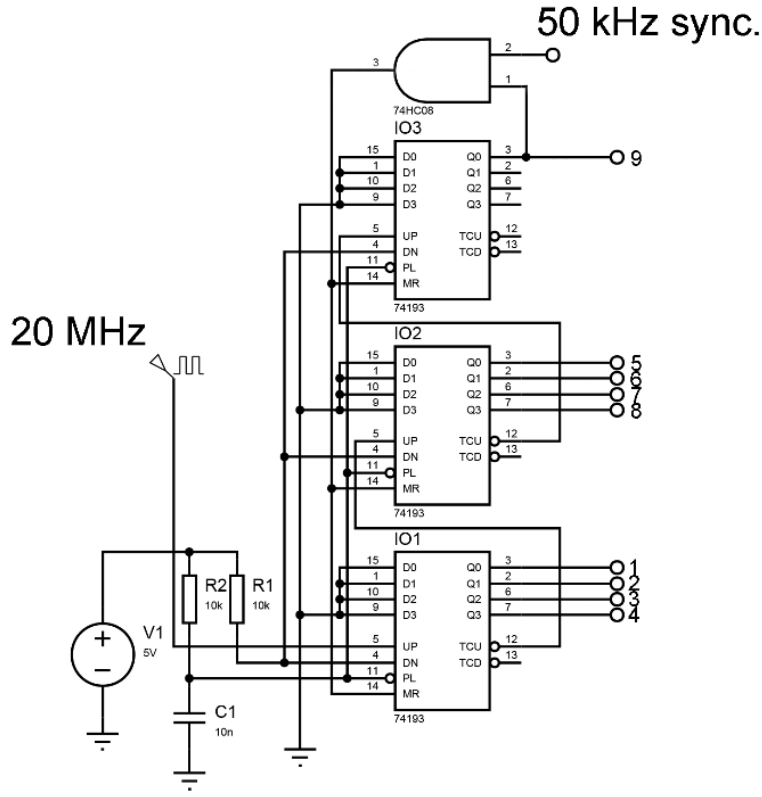

Fig. 5 Serial connection of the three 4-bit counters

The counter's output pins are interconnected with the inputs of three digital comparators connected in cascade and realized by IC 7485 (see Fig. 6). The 9-bit cascade comparator compares the desired value with the actual one in binary form. The actual value is obtained from the 9-bit counter outputs by the $A$ bus. The desired value is adjusted by the $B$ bus in the 9-bit digital form.

A

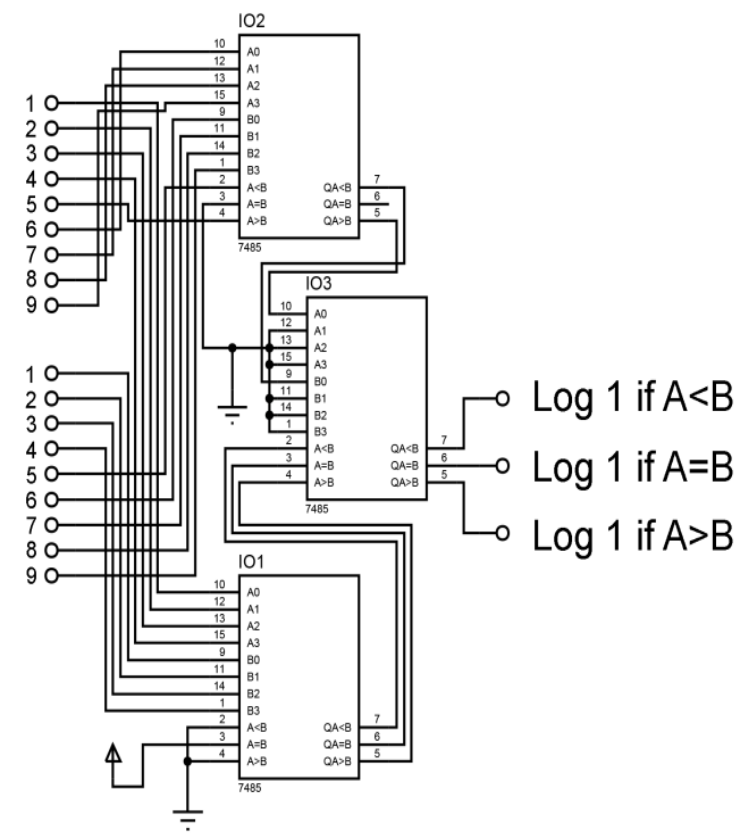

Fig. 6 Cascade connection of three digital comparators

The comparator provides three outputs. The first output has level $\log .1$, only at the moment, when the actual value is less, than desired. The second output is setting level log. 1, when the actual and desired values are equal. The third output sets $\log$. 1 , in the case when the actual value is greater than the desired one. For the desired PWM signal generation, it is possible to use the mentioned outputs.

The figure (see Fig. 7) illustrates the design of the one leg of the generator.

As was discussed, the pulse width control is possible to set by setting the digital inputs on $B$ bus. It can be done for example by any microprocessor that has at least $9 \mathrm{I} / \mathrm{O}$ pins. In such way, the microprocessor doesn't need to contain the PWM modulation ability.

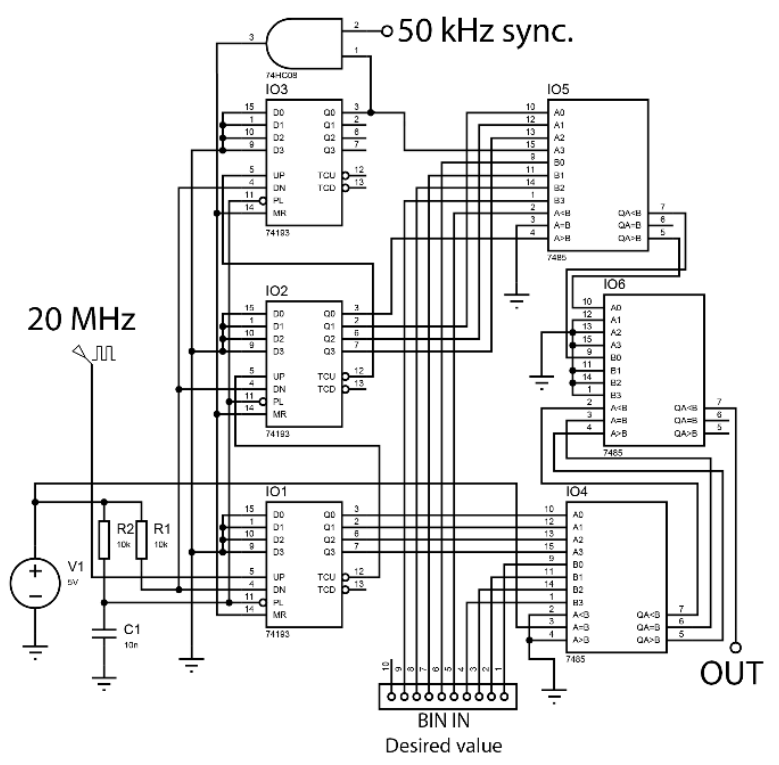

Fig. 7 One leg of the designed generator

\section{SIMULATION RESULTS}

The simulation model of the designed generator was created in Proteus 8 Professional simulation environment. This simulation program is able to simulate program including the microprocessor. The following simulations are performed with the help of ATmega328 microprocessor. The microprocessor had set values corresponding to the desired width of PWM in binary form, which are connected to the comparators. The comparators evaluate actual and desired values and generate output pulses.

The following two figures illustrate the simulation results obtained from a divider and legs of generator.

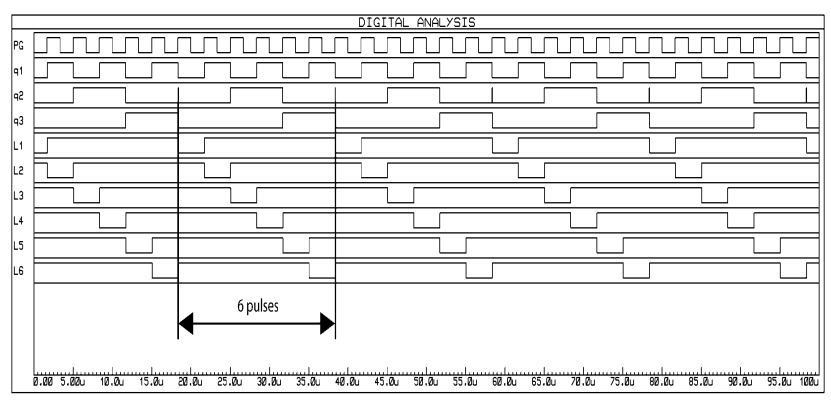

Fig. 8 Output signals from generator LTC1799 (PG), counter IC 74193 (q1-q3) and 10-bit decoder IC 7442 (L1-L6) 


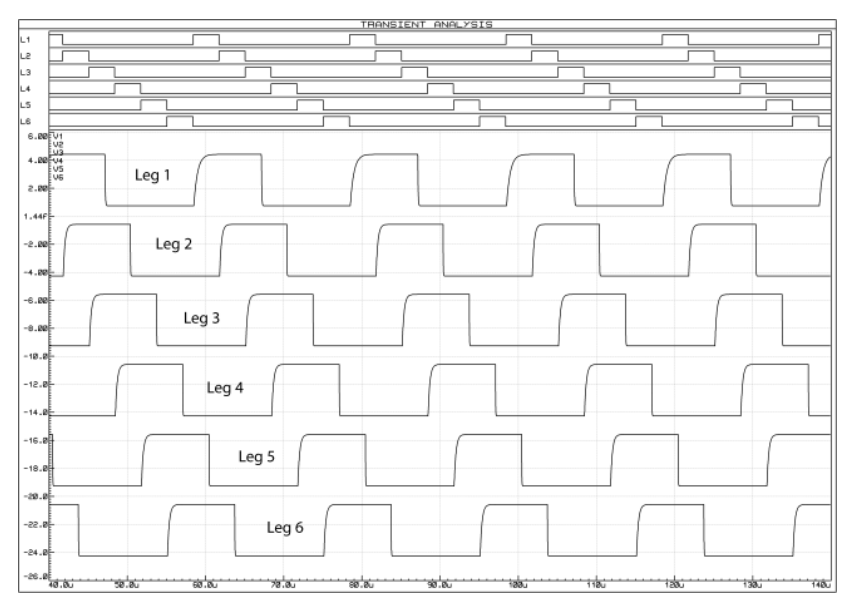

Fig. 9 Output inverted signals from decoder IC 7442 (L1-L6) and output signals from comparators IC 7485 (Leg1-Leg6)

\section{EXPERIMENTAL RESULTS}

The constructed prototype of generator was built and tested to verify the right principle of its operation.

The following oscillograms fully confirm the theoretical and simulation assumptions. The real microprocessor ATmega328 was used as a data entry circuit, similar as in the simulation.

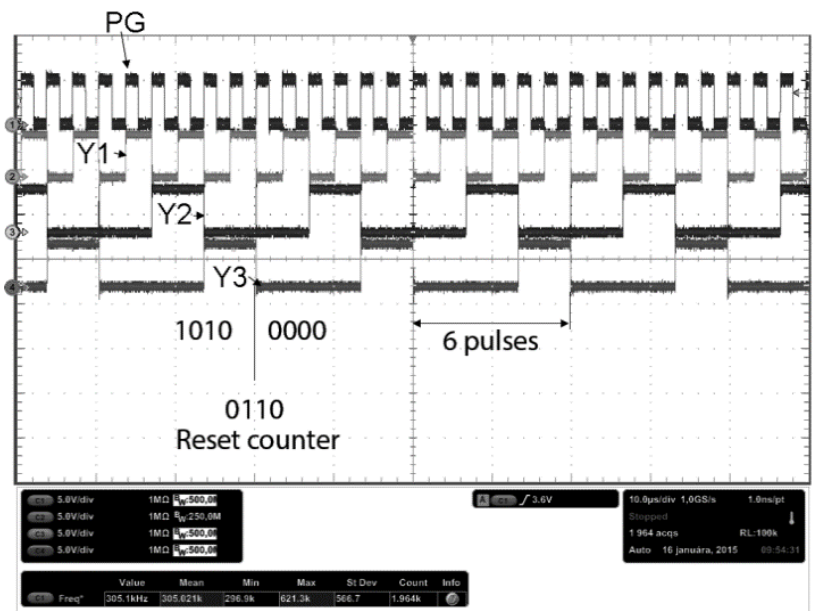

Fig. 10 Output signals from generator LTC1799 (PG) and counter IC 74193 (Y1-Y3)

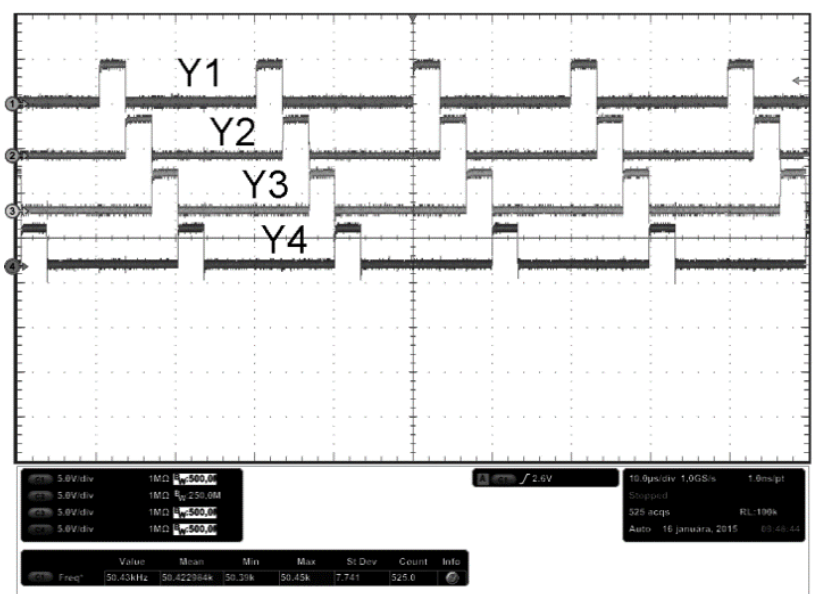

Fig. 11 Inverted output signals from the IC 7442 decoder

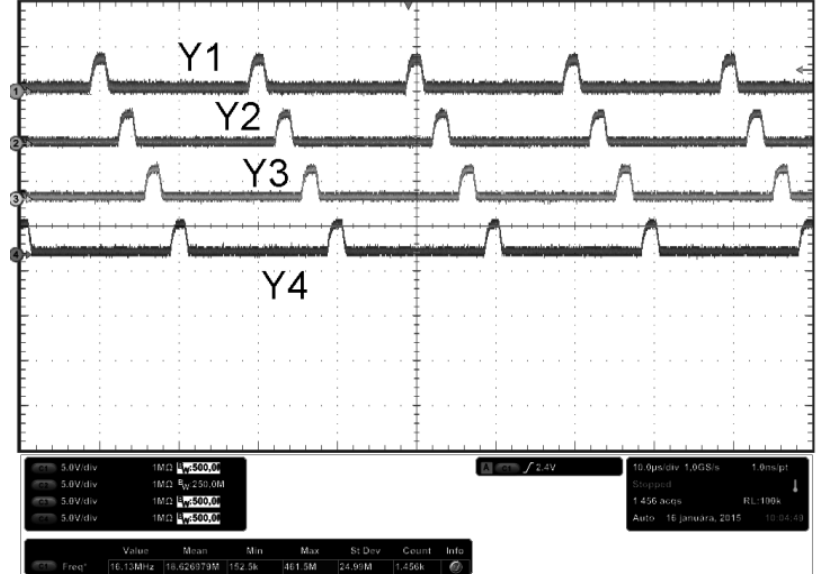

Fig. 12 PWM signals from comparator IC 7485

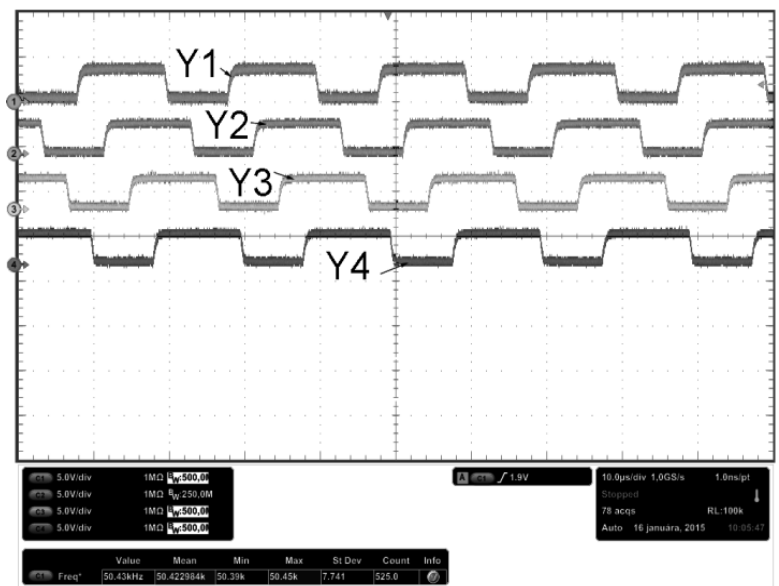

Fig. 13 PWM signals from the IC 7485 comparator

\section{PROPOSED PRINTED CIRCUIT BOARD}

PCB (Printed Circuit Board) design was created in the Proteus 8 Pro environment (see Fig. 14).

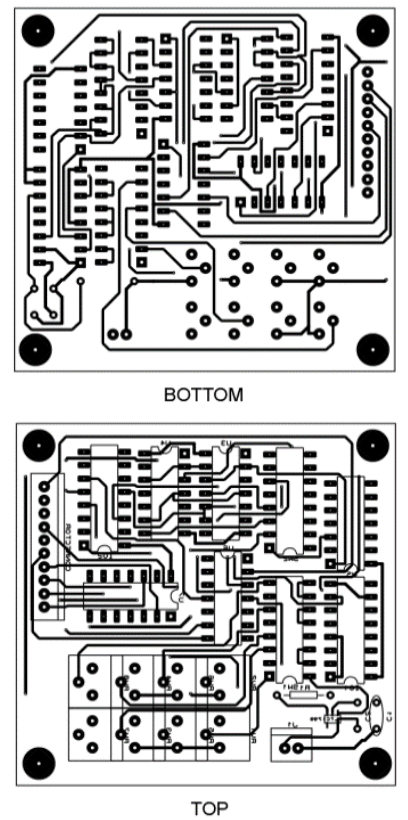

Fig. 14 Both sides of the designed PCB (divider) 


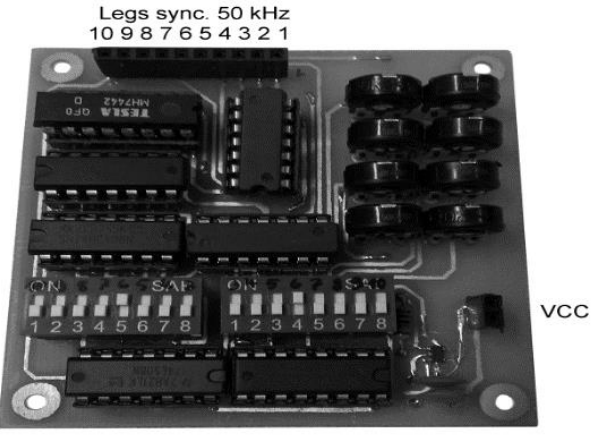

Fig. 15 Practical construction and design of the pulse divider

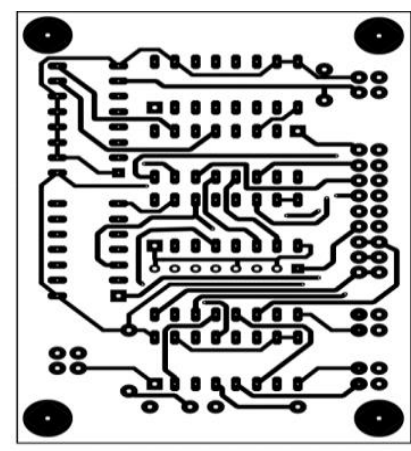

BOTTOM

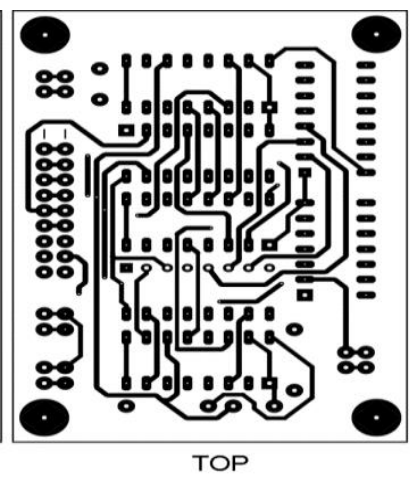

TOP
Fig. 16 Both sides of the PCB of the proposed PWM generator leg

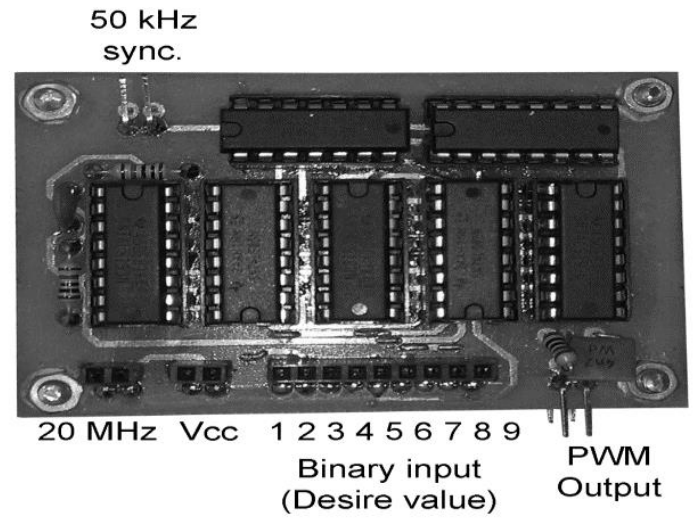

Fig. 17 Practical construction and design of the PWM generator, top view

Based upon the chosen concept of designed and realized generator, it is very easy to change the required number of legs, (see Fig. 18).

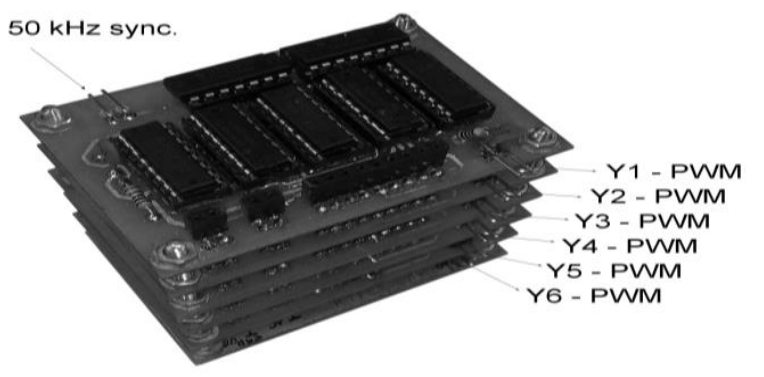

Fig. 18 Practical construction and design of the multi leg PWM generator

\section{CONCLUSIONS}

The results obtained by the simulation and from realized measurements are confirming the operational correctness of designed and realized generator, which can be used for control of multi-phase buck-boost converters. The structure is designed in such a way, to be able to easily change the number of legs, number of discrete states of width at PWM and also the output frequency, which can reach up to hundreds of $\mathrm{kHz}$. Control of this concept is provided easily by the 8-bit microprocessors. It means that the design doesn't require expensive or very fast microprocessor. Because of this it is possible to realize the generator, which is inherently cheap and sufficiently precise.

\section{ACKNOWLEDGEMENT}

The paper has been prepared under support of Slovak grant project KEGA No. 015TUKE-4/2015.

\section{REFERENCES}

[1] PERDULAK, J. - KOVÁČ, D. - KOVÁČOVÁ, I. OCILKA, M. - GLADYR, A. - MAMCHUR, D. ZACHEPA, I. - VINCE, T. - MOLNÁR, J.: Effective utilization of photovoltaic energy using multiphase boost converter in comparison with single phase boost converter. In: Communications, no. 3(2013), pp. 3238, Žilinská univerzita, ISSN 1335-4205

[2] PERDUL'AK, J. - KOVÁČ, D.: Comparison of efficiency of energy conversion of different topology of boost converters. In: Electromechanical and energy systems, modeling and optimization methods. Proceedings of the 11th international conference of students and young researchers, Kremenchuk 2013, pp. 71-72, ISBN 2079-5106

[3] Datasheet LTC1799, Linear Technology Corporation 1630 McCarthy Blvd., Milpitas, CA 95035-7417

[4] KOVÁČ, D. - KOVÁČOVÁ, I. - PERDULAK, J. VINCE, T. - MOLNÁR, J.: Analogue impulse generator for multi legs buck-boost DC/DC converter, Patent application No. 00008-2012

[5] PERDUL'AK, J. - KOVÁČ, D. - MELNYKOV, V.: A novel multiphase boost converter with high energy efficiency. In: Electromechanical and energy saving systems: Quarterly research and production journal Vol. 2011, No. 2 (2011), pp. 96-100, ISSN 2072-2052

[6] KOVÁČ, D. - KOVÁČOVÁ, I. - PERDULAK, J. VINCE, T. - MOLNÁR, J.: Control generator of impulses for multi legs boost DC/DC converter. Patent application No. 00097-2011

[7] KOVÁČOVÁ, I. - KOVÁČ, D.: Multi-legs boost DC/DC converter. Patent application No. 00150-2010

[8] BAČKO, M. - KOVÁČ, D.: Influence of shading and array orientation to photovoltaic energy production. In: Electromechanical and Energy Systems, Modelling and Optimization Methods: conference proceedings: 9th International conference of students and young researches, Kremenchuk, April 2011, pp. 58-59, ISSN 2079-5106 
[9] BAČKO, M.: Theoretical analysis of photovoltaics and wind energy application. In: ELITECH '10: 12th Conference of Doctoral Students: Bratislava, May 2010, Bratislava, pp. 1-6, ISBN 978-80-227-3303-8

[10] KAŇUCH, J. - VIŠNYI, P.: EMC of universal DC motor. In: Zeszyty Problemove: Maszyny Elektryczne. No. 88 (2010), pp. 209-215, ISSN 02393646

[11] KAŇUCH, J.: EMC of universal motor for AC and DC power supply. In: ISEM 2009: 17th International Symposium on Electric Machinery: Czech Technical University, Prague, 2009, pp. 117-123, ISBN 978-80010-4417-9

[12] DOBRUCKÝ, B. - BEŇOVÁ, M. - ŠPÁNIK, P.: Using Complex Conjugated Magnitudes- and Orthogonal Park/Clarke Transformation Methods of DC/AC/AC Frequency Converter. In: Electronics and Electrical Engineering, Kaunas: Technologija, 2009, No. 5(93), pp. 29-34

[13] S̆PÁNIK, P. - DRGOŇA, P. - FRÍVALDSKÝ, M. PRÍKOPOVÁ, A.: Design and Application of Full Digital Control System for LLC Multiresonant Converter. In: Electronics and Electrical Engineering, Kaunas: Technologija, 2010, No. 10(106), pp. 75-78

Received January 22, 2015, accepted February 17, 2015

\section{BIOGRAPHIES}

Matej Bereš was born on 10.06.1990. In 2014 he graduated (Ing.) with distinction at the Department of Theoretical and Industrial Electrical Engineering of the Faculty of Electrical Engineering and Informatics at Technical University in Košice (FEI TUKE). He defended his Diploma thesis in the field of Industrial engineering; his thesis title was "Autonomous mobile robot with obstacles prediction“. Since 2014 he is PhD Student at Department of Theoretical and Industrial Electrical Engineering of the FEI TUKE. The subject of his research is control algorithm of multiphase buck-boost converter.

Dobroslav Kováč - He finished his studies in 1985 at the Technical University of Košice, Department of Electrical Drives, area - Power electronics with excellent evaluation. Then he worked as a research worker at the Department of Electrical Drives. His research work was focused on the practical application of new power semiconductor devices. In 1989 he got the Award of the Minister of Education for the Development of Science and Technology. From 1991 he has worked as assistant lecturer at the Department of Theoretical Electrical Engineering and Electrical Measurement. He got his doctoral diploma in 1992 for the work on the field of power electronics. From 2000 he has worked as professor and his working interest is now focused mainly on the field of computer simulation of power electronic circuits and automated computer measuring. 